\title{
Ultra-High Modulus and Strength Films of High Molecular Weight Polypropylene Obtained by Drawing of Single Crystal Mats
}

\author{
Tetsuo Kanamoto, Akeharu Tsuruta, Koji TANAKA, \\ and Masatami TAKEDA \\ Department of Chemistry, Science University of Tokyo, \\ Kagurazaka, Shinjuku-ku, Tokyo 162, Japan
}

(Received October 24, 1983)

\begin{abstract}
KEY WORDS Ultrahigh Molecular Weight Polypropylene / Single Crystal / Coextrusion / Postdrawing / High Draw Ratio / Ultrahigh Modulus and Strength /
\end{abstract}

Several techniques ${ }^{1-7}$ of ultradrawing semicrystalline polymers have been applied to isotactic polypropylene for exploring the ultimate mechanical properties. The maximum tensile moduli and strengths attained by these processes for polypropylene were in the range of $15-22 \mathrm{GPa}^{1-6}$ and $0.46-0.93 \mathrm{GPa}^{1,7}$ respectively. In our previous papers, ${ }^{8-10}$ we showed that single crystal aggregates of high density polyethylene, grown from dilute solutions in xylene, can be effectively drawn up to uniaxial draw ratios (DR) of 45-300 (at $110^{\circ} \mathrm{C}$ ), with a maximum achievable DR increasing with polyethylene molecular weight (MW). Furthermore, ultrahigh MW polyethylene in the form of single crystal mats was deformable up to a DR 250-300 by postdrawing of the mats after extrusiondrawing to a low draw ratio (EDR). Such superdrawn films exhibited extreme tensile moduli, up to $222 \mathrm{GPa}$, which approached an yet uncertain theoretical modulus of a perfect polyethylene crystal $(240-324 \mathrm{GPa}){ }^{11-13}$

In a study describing in this communication, we applied this two-stage drawing technique to ultrahigh molecular weight polypropylene (UHMW-PP) crystals grown from dilute solutions in xylene. The mats produced there- from were effectively drawn to a DR as high as 66. Such superdrawn films exhibited tensile moduli and strength, up to $33 \mathrm{GPa}$ and $1.5 \mathrm{GPa}$, respectively. These tensile properties are substantially higher, $50 \%$, than those previously reported for polypropylene. ${ }^{1-7}$ Furthermore, the maximum modulus achieved in this work ( $33 \mathrm{GPa}$ ) closely approached the theoretical modulus of the monoclinic polypropylene lattice reported to be $35-42 \mathrm{GPa}^{11,14}$

\section{EXPERIMENTAL}

The UHMW-PP used was an experimental sample kindly supplied by Toa Nenryo Kogyo Co., Ltd. The viscosity average MW was $\sim 2 \times 10^{6}$. Solution grown crystals (SGC) of UHMW-PP were isothermally precipitated from dilute solutions $(\leqq 0.2 \mathrm{wt} \%)$ in xylene kept at $55^{\circ} \mathrm{C}$ over $20 \mathrm{~h}$. The polymer was stabilized with $0.5 \mathrm{wt} \%$ (based on the polymer) of an antioxidant, 2,6-di-t-butyl-p-cresol. Sedimented SGC mats were obtained by slowly filtering the crystal suspension followed by drying in vacuo at room temperature for one week. Melt-crystallized (MGC) sheets were compression molded at $200^{\circ} \mathrm{C}$ for $5 \mathrm{~min}$, and then slowly cooled to room temperaure. 
A two-stage drawing technique ${ }^{9}$ was used for drawing SGC mats and MGC sheets of UHMW-PP. For the first-stage drawing, the solid-state coextrusion technique developed by Porter et al. ${ }^{15}$ was used. One or two mats (or sheets) were placed between two split billet halves of normal MW polyethylene and the assembly coextruded at $130^{\circ} \mathrm{C}$. The definition of extrusion draw ratio (EDR) and experimental methods have been described ${ }^{8,9,15}$ For the second stage, a conventional tensile drawing technique was used. Extrudates having an EDR of $3.4-25$, and $2-5 \mathrm{~mm}$ wide and 5$50 \mathrm{~mm}$ long were drawn isothermally on a Tensilon tensile tester HTM-100 at constant temperatures from $26-160^{\circ} \mathrm{C}$ and at constant extension cross-head speeds of $5-10 \mathrm{~mm}$ $\min ^{-1}$. The total draw ratio $\left(D R_{t}\right)$ following the final-stage draw is defined by $D_{t}=$ $\mathrm{EDR} \times \mathrm{DR}$.

Tensile properties of two-stage processed films along the fiber axis were measured at room temperature $\left(\sim 26^{\circ} \mathrm{C}\right)$ and at a strain rate of $\sim 1 \times 10^{-3} \mathrm{~s}^{-1}$. The modulus was determined from the slope of the stress-strain curve at low strain $(<0.1 \%)$. The crosssectional area of a sample $\left(10^{-1}-10^{-3} \mathrm{~mm}^{2}\right)$ was calculated from the sample weight, length, and density.

\section{RESULTS AND DISCUSSION}

The effect of initial morphology on the drawability of UHMW-PP was studied first. The MGC sheets and SGC mats were drawn at $130^{\circ} \mathrm{C}$ by three techniques; i.e., by a conventional tensile drawing, solid-state coextrusion, and by their combination, the twostage drawing. The maximum achievable DR for the MGC sheet was $8-12$ at $130^{\circ} \mathrm{C}$ and was not significantly affected by the drawing techniques. The drawability for the SGC mats was much higher than for the MGC sheets. The concentration of solutions in the range from 0.05 to $0.2 \%$ used for solution crystallization, had no significant effect on the draw-

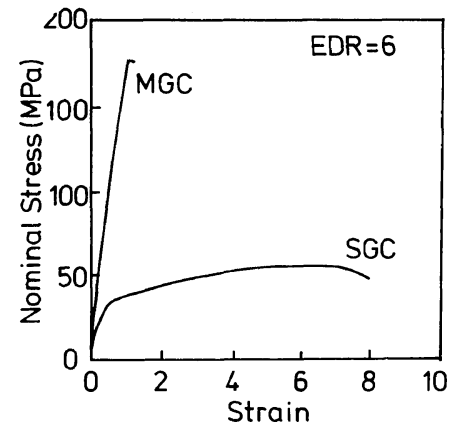

Figure 1. Nominal stress-strain curves for the postdrawing of the MGC and SGC extrudates with EDR 6 recorded at $130^{\circ} \mathrm{C}$ and at a cross-head speed of $5 \mathrm{~mm} \mathrm{~min}{ }^{-1}$. The initial gauge length was $10-15 \mathrm{~mm}$.

ability of the SGC mats of UHMW-PP. The drawability, however, was greatly influenced by the drawing technique. The maximum achievable DR for the SGC mats at $130^{\circ} \mathrm{C}$ was 25-35 for a single-stage drawing by the solidstate coextrusion or by the conventional tensile drawing. The extrusion of the mats to a low EDR (3-6) remarkably improved the subsequent tensile drawability, and a $\mathrm{DR}_{\mathrm{t}}$ up to 66 could be achieved by the two-stage draw. No such high $D_{t}$ was achieved for the postdrawing of higher EDR extrudates (EDR $\geqq 12$ ). A similar behavior has been observed in the superdrawing of single crystal mats of UHMW-polyethylene. ${ }^{9,10}$ Thus, the postdrawing of the EDR 6 extrudate should be emphasized.

The effect of initial morphology on drawing behavior is seen on the nominal stress-strain curves shown in Figure 1. These curves were recorded at $130^{\circ} \mathrm{C}$ for the second-stage tensile drawing of the EDR 6 samples prepared from the SGC mats and MGC sheets at $130^{\circ} \mathrm{C}$. The draw stress of the MGC extrudate increases rapidly with drawing until the fracture occurs at a strain of $\sim 100 \%\left(\mathrm{DR}_{\mathrm{t}}\right.$ of $\left.6 \times 2=12\right)$. In contrast, the stress-strain behavior of the SGC extrudate is characterized by a lower stress and a higher strain at break of $830 \%$, a markedly higher $\mathrm{DR}_{\mathrm{t}}(6 \times 9.3=56)$ for the SGC ex- 


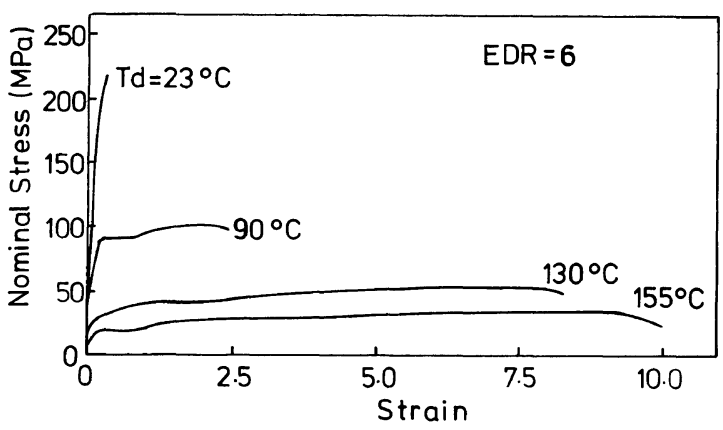

Figure 2. Nominal stress-strain curves for the postdrawing of the SGC extrudates with EDR 6 recorded at the temperature range of 23 to $155^{\circ} \mathrm{C}$ and at a cross-head speed of $5 \mathrm{~mm} \mathrm{~min}^{-1}$. The initial gauge length was $10-20 \mathrm{~mm}$.

trudate. The strain hardening phenomenon, usually observed for drawing melt-crysrallized polymers, was absent in the postdrawing of the extruded SGC mats as well as in the tensile drawing of the as-prepared SGC mats.

Another important parameter which affects the drawability and the resultant properties is the draw temperature. Figure 2 shows nominal stress $v s$. strain curves recorded at constant temperatures over the 26 to $155^{\circ} \mathrm{C}$ range for the final-stage tensile drawing of the SGC mats extruded to an EDR 6 at $130^{\circ} \mathrm{C}$. With increasing temperature, the draw stress decreases and the deformability increases remarkably. The maximum achievable $D_{t}$ abruptly increases between 90 and $130^{\circ} \mathrm{C}$. This improvement of the drawability is related to the crystal softening (crystal $\alpha$-dispersion) observed at $\sim 130^{\circ} \mathrm{C}$ in the dynamic mechanical measurements of the SGC mats and drawn samples. ${ }^{16}$ Thus, the normal limit for the maximum achievable DR of UHMW-PP at $130^{\circ} \mathrm{C}$ increased from $\sim 12$ for the melt-crystallized form to $25-35$ for the single-stage drawing of the solution-grown crystals. The application of the two-stage drawing process furtehr improved the drawability of the SGC mats and allowed us to achieve a $\mathrm{DR}_{\mathrm{t}}$ up to $56-66$ in the temperature range $130-160^{\circ} \mathrm{C}$.

There are difficulties in measurement of the tensile properties of highly-drawn, ultra-thin, uniform-dimension, films of high modulus and

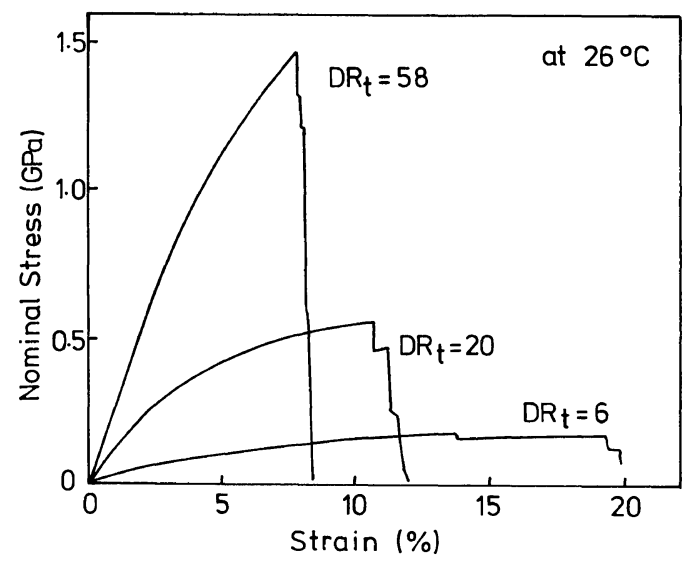

Figure 3. Nominal stress-strain curves for the twostage processed films recorded at room temperature and at a strain rate of $\sim 1 \times 10^{-2} \mathrm{~s}^{-1}$. The initial gauge length was $5-10 \mathrm{~cm}$.

strength. The following procedures ${ }^{9}$ were used to avoid the sample slippage and the fracture at the edge of the cramp during a measurement. For the measurement of tensile modulus, two ends, $2 \mathrm{~cm}$ long, of drawn films of 10 $15 \mathrm{~cm}$ long was sandwitched with a small amount of super-glue between two pieces of sandpaper having a fine grain size. Even in this arrangement, however, the highly drawn films always fractured at the edge of cramp. Thus, for the measurement of tensile strength at break, the two ends of a film were partially oxidized in solution of sulfuric acid potassium chlomate at $70^{\circ} \mathrm{C}$ for $\sim 2 \mathrm{~min} .{ }^{17}$ The ends were 
T. KanAMOTO et al.

Table I. Tensile properties of superdrawn UHMW-PP films

\begin{tabular}{|c|c|c|c|c|c|}
\hline Drawing & \multirow{2}{*}{ Initial EDR } & \multirow{2}{*}{$\frac{\text { Total draw ratio }}{\mathrm{DR}_{\mathrm{t}}=\mathrm{EDR} \times \mathrm{DR}}$} & \multirow{2}{*}{$\frac{\text { Modulus }}{\mathrm{GPa}}$} & \multirow{2}{*}{$\frac{\text { Strength }}{\mathrm{GPa}}$} & \multirow{2}{*}{$\frac{\text { Strain at break }}{\%}$} \\
\hline${ }^{\circ} \mathrm{C}$ & & & & & \\
\hline - & $6.0^{\mathrm{a}}$ & 6 & 6 & 0.2 & 20 \\
\hline 90 & 6.0 & 20 & 16 & 0.5 & 10 \\
\hline 130 & 3.4 & 56 & 28 & 1.2 & 7 \\
\hline 130 & 6.0 & 52 & 26 & 1.0 & 6 \\
\hline 155 & 3.4 & 50 & 25 & 1.5 & 12 \\
\hline 155 & 6.0 & 31 & 22 & - & - \\
\hline 155 & 6.0 & 66 & 33 & 1.5 & 6 \\
\hline 160 & 6.0 & 63 & 30 & 1.2 & 6 \\
\hline 160 & 6.0 & 58 & 30 & 1.4 & 7 \\
\hline
\end{tabular}

a Extrudate with EDR 6 prepared at $130^{\circ} \mathrm{C}$ and used for the postdrawning.

then sandwitched with epoxy between two brass plates. The polar groups introduced on the surface of the film improved bonding with epoxy. This assembly was tightly fixed on cramps and mounted on a tensile tester.

Figure 3 shows typical stress-strain curves for two-stage processed films recorded at room temperature and at a strain rate of $\sim 1 \times 10^{-2} \mathrm{~s}^{-1}$. The fracture commonly developed by a repetitive partial rupture resulting in an extensive fibrillation. This feature was most prominent for highly drawn films, and was reflected in the stress-strain curves at high strain where the stress decreased stepwise. The tensile strengths and the strains at break calculated from these curves are listed in Table I. The tensile modulus was determined from a separate set of stress-strain tests. A DT $\geqq 50$ was achieved in the temperature range from 130 to $160^{\circ} \mathrm{C}$. Under these conditions, a modulus $\geqq 25 \mathrm{GPa}$ and a strength $\geqq 1 \mathrm{GPa}$ were obtained by the two-stage drawing. The highest tensile modulus and strength recorded in this work were 33 and $1.5 \mathrm{GPa}$, respectively. These values are $50 \%$ higher than previously reported for polypropylene. ${ }^{1-7}$ Furthermore, the modulus was close to the theoretical lattice modulus of a perfect polypropylene crystal (35- $42 \mathrm{GPa}){ }^{11,14}$

$\mathrm{X}$-Ray photographs showed that the crystal structures of both as-prepared single crystal mats and highly-drawn films were the stable monoclinic form. The density of the highest modulus sample measured in a density gradient column at $30^{\circ} \mathrm{C}$ was $\sim 0.915 \mathrm{~g} \mathrm{~cm}^{-3}$, slightly higher than the initial SGC mats $\left(0.910 \mathrm{~g} \mathrm{~cm}^{-3}\right)$. It should be noted that the draw ratio required to achieve the moduli approaching the lattice modulus was $\sim 250$ for UHMW-polyethylene ${ }^{9,10}$ and $\sim 70$ for UHMW-PP. Previously, ${ }^{18}$ we have discussed the minimum draw ratio $\mathrm{DR}_{\min }$ necessary for full chain extension. $\mathrm{DR}_{\text {min }}$ varied markedly in value and in trend with the choice of deformation mode. However, the $\mathrm{DR}_{\min }$ calculated on the basis of drawing from a random coil geometry was close to the actual superdraw process for single crystal mats of UHMWpolyethylene. Thus, the $\mathrm{DR}_{\text {min }}$ was calculated for polypropylene MW's on the basis of the random coil model, yielding 64-100 for the MW range of $1-2.5 \times 10^{6}$. Because of the uncertainty in the molecular weight $\left(\sim 2 \times 10^{6}\right)$ determined from the viscosity measurement for the present UHMW-PP sample which had a broad MW distribution, it may be concluded that the experimental draw ratio $(\sim 70)$ required to achieve the maximum modulus favorably compares with the calculated $\mathrm{DR}_{\text {min }}$.

In conclusion, aggregates of UHMW-PP single crystal, precipitated from dilute so- 
lutions, exhibit a high drawability, just as previously observed for UHMW-polyethylene. The most efficient drawing for the SGC mats of UHMW-PP was achieved by the two-stage drawing technique, i.e., solid-state coextrusion to a low EDR followed by tensile drawing. Thus, UHMW-PP could be drawn at about $130^{\circ} \mathrm{C}$ up to an extreme DR of 66 . Such highlydrawn films exhibited tensile moduli $\leqq 33 \mathrm{GPa}$ and strength $\leqq 1.5 \mathrm{GPa}$. The maximum modulus was comparable to the reported theoretical lattice modulus of a polypropylene crystal.

Acknowledgment. We are greatly indebted to Professor Roger S. Porter, University of Massachusetts, U.S.A., for valuable discussion, comments and suggestions.

\section{REFERENCES}

1. T. Williams, J. Mater. Sci., 8, 59 (1973).

2. W. N. Taylor and E. S. Clark, Polym. Eng. Sci., 18, 518 (1978).

3. M. Kamezawa, K. Yamada, and M. Takayanagi, $J$. Appl. Polym. Sci., 24, 1227 (1979).
4. R. J. Samuels, J. Polym. Sci., Polym. Phys. Ed., 17, 535 (1979).

5. K. Nakayama, H. Kanetsuna, and E. Noda, J. Jpn. Soc. Technol. Plast., 20, 820 (1979).

6. A. J. Wills, G. Capaccio, and I. M. Ward, J. Polym. Sci., Polym. Phys. Ed., 18, 493 (1980).

7. T. Kunugi, J. Polym. Sci., Polym. Lett. Ed., 20, 329 (1982)

8. T. Kanamoto, E. S. Sherman, and R. S. Porter, Polym. J., 11, 497 (1979).

9. T. Kanamoto, A. Tsuruta, K. Tanaka, M. Takeda, and R. S. Porter, Polym. J., 15, 327 (1983).

10. T. Kanamoto, A. Tsuruta, K. Tanaka, M. Takeda, and R. S. Porter, Rep. Prog. Polym. Phys. Jpn., 26, 347 (1983).

11. I. Sakurada, T. Ito, and K. Nakamae, J. Polym. Sci., C, 31, 57 (1966).

12. A. Odajima and T. Maeda, J. Polym. Sci., C, 15, 55 (1966).

13. G. Wobser and S. Blasenbrey, Kolloid Z-Z, Polym., 241, 985 (1970).

14. I. Sakurada and K. Kaji, J. Polym. Sci., C, 31, 57 (1970).

15. P. D. Griswold, A. E. Zachariades, and R. S. Porter, Polym. Eng. Sci., 18, 861 (1978).

16. A. Tsuruta, T. Kanamoto, K. Tanaka, M. Takeda, and R. S. Porter, to be published.

17. S. R. Allen and R. S. Porter, private communication.

18. T. Kanamoto and R. S. Porter, J. Polym. Sci., Polym. Phys. Ed., in press. 